\title{
Lacy Reticular-pattern Calcinosis in Adult Dermatomyositis
}

CINDY H. FLOWER, MBBS, DM; AVONELLO A. MAYNARD, MD, Faculty of Medical Sciences, The University of the West Indies, Cave Hill Campus, St. Michael, Barbados. Address correspondence to Dr. Flower; E-mail: cflower@caribsurf.com. J Rheumatol 2013;40:1406; doi:10.3899/jrheum.130042

Dermatomyositis (DM) is an autoimmune connective tissue disease associated with calcinosis, uncommon in adults. A 61-year-old African Caribbean woman with a 6-year history of DM presented with a 1-year history of thickening of the skin and subcutaneous tissue of the upper limbs, the chest and abdominal wall, and both thighs. There were flexion contractures at the elbows, bilateral frozen shoulders, and muscle wasting.

Radiographs demonstrated lacy reticular subcutaneous calcification along the chest and abdominal walls and in the subcutaneous tissue and muscles of the upper limbs (Figure 1).

$\mathrm{DM}$ is one of the most common autoimmune connective tissue diseases associated with calcinosis, which is typically distributed in the trunk and extremities and is less prevalent, with a later onset, in adults compared to children ${ }^{1}$. The classic description is of a diffuse fine reticular-pattern cal- cinosis, in contrast to the localized lobular masses that may be seen in tumoral calcinosis ${ }^{2}$. The diffuse, subcutaneous, lacy, reticular calcinosis is one of 4 distinct patterns of soft-tissue calcification described in juvenile DM; however, evidence in adults is not mentioned in the literature ${ }^{3}$.

\section{REFERENCES}

1. Balin SJ, Wetter DA, Andersen LK, Davis MD. Calcinosis cutis occurring in association with autoimmune connective tissue disease: The Mayo Clinic experience with 78 patients, 1996-2009. Arch Dermatol 2012;148:455-62.

2. Gutierrez A Jr, Wetter DA. Calcinosis cutis in autoimmune connective tissue diseases. Dermatol Ther 2012;25:195-206.

3. Blane CE, White SJ, Braunstein EM, Bowyer SL, Sullivan DB. Patterns of calcification in childhood dermatomyositis. AJR Am J Roentgenol 1984;142:397-400.
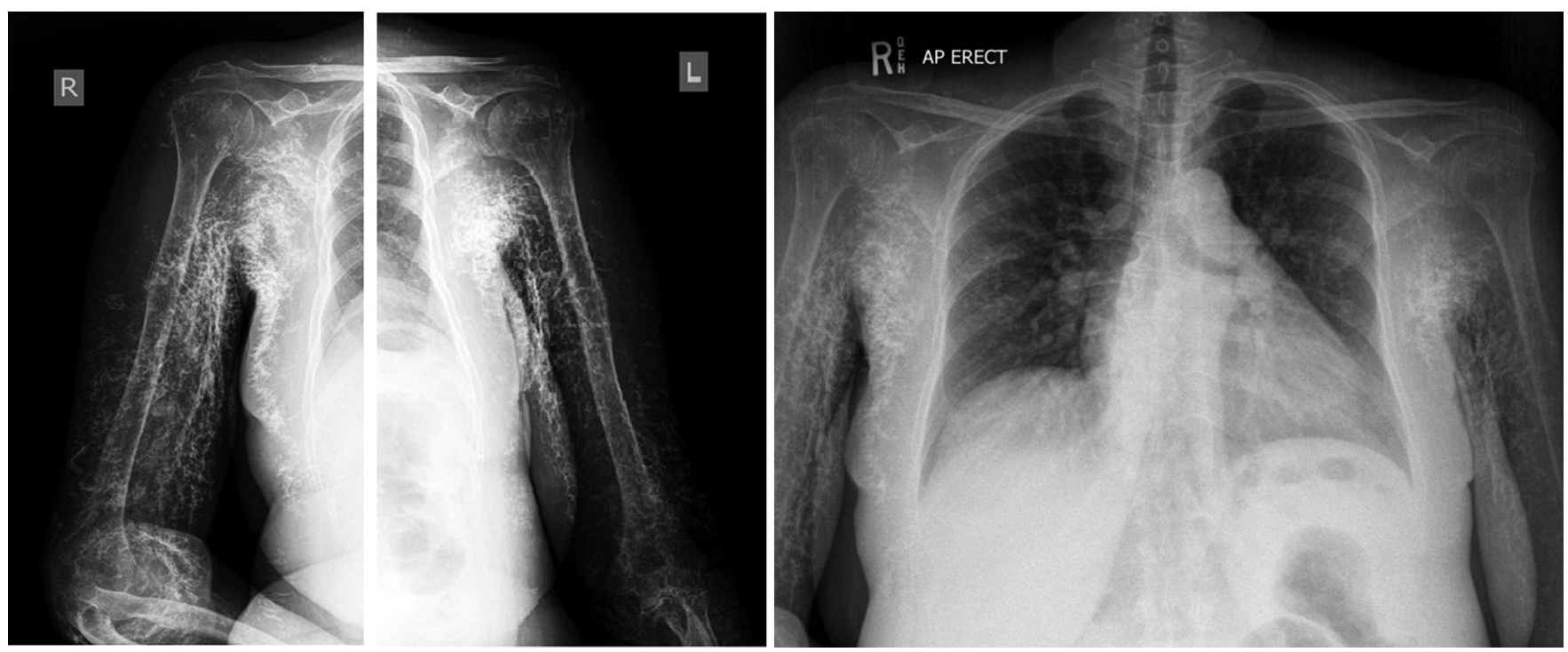

Figure 1. Lacy reticular-pattern calcinosis in the subcutaneous tissue and intramuscular region of the chest wall and upper limbs. 